NBER WORKING PAPER SERIES

WATER DEMAND UNDER ALTERNATIVE PRICE STRUCTURES

\author{
Sheila Olmstead \\ W. Michael Hanemann \\ Robert N. Stavins \\ Working Paper 13573 \\ http://www.nber.org/papers/w13573
NATIONAL BUREAU OF ECONOMIC RESEARCH
1050 Massachusetts Avenue
Cambridge, MA 02138 \\ November 2007
}

This work was supported in part by grant \#SES-0095348 from the National Science Foundation, Economics Program. For comments and guidance, we are grateful to Li Gan, Tony Gómez-Ibáñez, Julie Hewitt, Jeffrey Liebman, Erin Mansur, Todd Olmstead, Ellen Pint, Bob Triest, Frank Wolak, Richard Zeckhauser, and seminar participants at Yale, Harvard, Stanford, the University of California, Santa Barbara, and the National Bureau of Economic Research. Special thanks to Arik Levinson and two anonymous referees, whose suggestions greatly improved the paper. Graeme Auld provided excellent research assistance. The authors, alone, are responsible for any remaining errors. The views expressed herein are those of the author(s) and do not necessarily reflect the views of the National Bureau of Economic Research.

(C) 2007 by Sheila Olmstead, W. Michael Hanemann, and Robert N. Stavins. All rights reserved. Short sections of text, not to exceed two paragraphs, may be quoted without explicit permission provided that full credit, including (C) notice, is given to the source. 
Water Demand Under Alternative Price Structures

Sheila Olmstead, W. Michael Hanemann, and Robert N. Stavins

NBER Working Paper No. 13573

November 2007

JEL No. D12,L95,Q21,Q25,Q28

\begin{abstract}
$\underline{\text { ABSTRACT }}$
We estimate the price elasticity of water demand with household-level data, structurally modeling the piecewise-linear budget constraints imposed by increasing-block pricing. We develop a mathematical expression for the unconditional price elasticity of demand under increasing-block prices and compare conditional and unconditional elasticities analytically and empirically. We test the hypothesis that price elasticity may depend on price structure, beyond technical differences in elasticity concepts. Due to the possibility of endogenous utility price structure choice, observed differences in elasticity across price structures may be due either to a behavioral response to price structure, or to underlying heterogeneity among water utility service areas.
\end{abstract}

\author{
Sheila Olmstead \\ Yale School of Forestry \\ \& Environmental Studies \\ Robert N. Stavins \\ Sage Hall, 205 Prospect Street \\ New Haven, CT 06511 \\ JFK School of Government \\ Harvard University \\ sheila.olmstead@yale.edu \\ 79 JFK Street \\ Cambridge, MA 02138 \\ and NBER \\ W. Michael Hanemann \\ robert_stavins@harvard.edu \\ University of California \\ Depart. of Agricultural \& Resource Economics \\ 207 Giannini Hall \\ Berkeley, CA 94720 \\ hanemann@are.berkeley.edu
}




\section{WATER DEMAND UNDER \\ Alternative Price Structures}

\section{INTRODUCTION}

Water managers traditionally have maintained that consumers do not respond to price signals, so demand management has occurred most frequently through restrictions on specific water uses and requirements for the adoption of specific technologies. In theory, raising prices to bring about water conservation is less costly than implementing a command-and-control approach, even if the prices in question are inefficient. Water utilities increasingly hear this message and respond in many cases by implementing increasing block prices (IBPs), under which marginal prices increase with the quantity consumed. The price elasticity of water demand is a key variable of interest in this context, because: (1) regulators may use price to reduce demand during periods of scarcity; and (2) utilities often face zero-profit constraints, so the impact of price changes on total revenues is a concern.

In 2000, approximately one-third of U.S. urban residential water customers faced increasing block prices, up from four percent in 1982 [1], [2]. Consumer responses to IBPs in the market for water are unclear, at best. Estimating water demand functions under non-linear price regimes requires econometric techniques that can separate demand from supply. The problem is that marginal prices change as consumption increases, so that, while the price schedule is set by the supplier, the actual price paid by the consumer and the quantity consumed are simultaneously determined by the consumer.

Our analysis offers three main contributions to the economic literature on water demand. First, using the most price-diverse, detailed, household-level water demand data yet available, 
we exploit substantial variation in the price incentives faced by households to estimate price elasticities under increasing-block and uniform marginal prices. Using a structural model that accounts for non-linear prices, we estimate a full-sample price elasticity of water demand of approximately -0.33 . We are not the first to estimate a structural water demand model for consumers facing piecewise-linear budget constraints. However, previous applications have analyzed very restrictive samples. Ours is more broadly representative of U.S. urban residential water demand.

Second, we explore the ways in which the concept of price elasticity under non-linear prices differs from that under a typical single marginal price. We find that the price elasticity of demand under increasing-block prices is a complex function of the price and income elasticities of demand along particular budget segments. These results may be of some general interest, as non-linear prices predominate in markets for many goods and services other than water, including electricity, local and wireless telephone services, and labor supply under progressive income taxation.

Third, we consider the interesting and policy-relevant possibility that, aside from innate mathematical differences in what a price elasticity is measuring, household price elasticity may be a function of a utility's choice of price structure. Our examination of this question is prompted by: (1) some clues in meta-analyses in the water demand literature that suggest this could be the case; and (2) the fact that the three previous applications of structural estimation under non-linear prices have all resulted in high price elasticity estimates, relative to the mean in the literature. We perform two tests of this hypothesis. Results suggest that price elasticity may be a function of price structure. However, there are a number of complications in this 
determination which are described further below. What we observe may be a behavioral response to price structure, or it may be due to underlying heterogeneity among utilities adopting different price structures.

In large parts of the United States, scarce water supplies are a serious environmental concern. In some cases, water is being used at rates that may exceed those dictated by the efficiency criterion, particularly when externalities are considered. ${ }^{1}$ Cities in arid states such as Texas and California have struggled to manage scarcity in the face of population growth, as well as consumer demand for swimming pools, landscaping and other water-intensive amenities. The administratively-determined rate schedule sets water markets apart from many natural resource markets in which we would expect prices to reflect scarcity (e.g., oil and coal). Nonetheless, public agencies typically set water prices, thus the potential exists for establishment of rate structures that provide social-welfare-compatible incentives. This paper explores two important aspects of water pricing - how sensitive U.S. households are to changes in water prices, and whether price elasticity differs under alternative rate structures. Research in this area can provide critical information to water resource managers.

The paper is organized as follows. In Section 2, we review the literature on block pricing and the price elasticity of residential water demand. In Section 3 we describe the data, and in Section 4 we describe our models. In Section 5 we describe the results, and in Section 6 we conclude.

\section{The Literature AND The ECONOMic ConteXt}

\subsection{Block Pricing and Efficiency}

${ }^{1}$ For example, in many parts of the United States, annual water use is maintained by groundwater mining [3]. 
Urban residential water pricing typically takes one of three forms: (1) a uniform marginal price; (2) increasing block prices; or (3) decreasing block prices. Each of these price structures is typically accompanied by a fixed water service fee. Under a uniform price (UP), households pay a single volumetric marginal price at all levels of consumption. Increasing block structures charge higher marginal prices for higher quantities consumed, resulting in a water supply function that resembles a staircase ascending from left to right (Figure 1); decreasing block structures are stacked in the opposite direction.

Water prices in North America generally lie below the long-run marginal cost (LRMC) of water supply, the efficient price [4], [5]. Utilities' adoption of increasing block prices may expand the fraction of consumption priced at the LRMC. The LRMC can be greater than shortrun average cost, because LRMC reflects the cost of new supply acquisition, and new supplies are typically more costly to develop than current supplies [4]. Thus, pricing all units at LRMC may cause utility revenues to exceed current expenses, sometimes substantially [6], [7]. The efficient way to deal with this would be to rebate net revenues in some lump-sum fashion. IBPs instead charge something approaching LRMC for "marginal" uses (lawn-watering and the like), while meeting rate of return constraints through the manipulation of block cutoffs and inframarginal prices. Increasing the fraction of consumption that faces efficient prices would result in welfare gains. But even if the highest-tier price in an IBP schedule does reflect LRMC, some welfare losses must result from marginal subsidies to consumers facing lower-tier prices. Thus, the relative efficiency of uniform and IBP structures depends on many things.

Water prices are usually set by elected or appointed entities, such as city councils or, for the relatively small number of investor-owned water utilities, by public utility commissions. 
Consumers may or may not influence the adoption of particular price structures, and even the magnitude of marginal price, through the political process. ${ }^{2}$ We do not directly model the avenues through which water prices are set. Instead, we focus on the demand side - how estimates of elasticity capture different phenomena under different price structures, and whether consumers react differently to different price structures, establishing that endogenous price structure choice by utilities may be a serious obstacle to answering the second question.

\subsection{Consumer responses to water prices and price structure}

Previous analyses suggest that water demand is inelastic. In a meta-analysis of 124 estimates generated between 1963 and 1993, accounting for the precision of estimates, the mean price elasticity is -0.51 , the short-run median is -0.38 , and the long-run median is -0.64 , with 90 percent of all estimates between 0 and $-0.75[8] .^{3}$

Under block pricing, consumers face a piecewise-linear budget constraint. Figure 2 depicts the budget constraint in a two-tier increasing block price system with a set of hypothetical indifference curves. The consumer has three reasonable consumption choices: consume on the interior of segment one, on the interior of segment two, or at the kink point - the quantity at which the marginal price increase occurs. ${ }^{4}$

\footnotetext{
${ }^{2}$ For example, in the City of Corpus Christi, Texas, a local taxpayers' organization successfully lobbied for a regulation limiting water price increases by the public utility to the rate of inflation during the early 1990s, despite a series of severe regional droughts. In our experience, most of the citizen involvement in water rate setting has been aimed at preventing price increases, rather than promoting them.

${ }^{3}$ In a more recent meta-analysis of almost 300 price elasticity studies, $1963-1998$, the mean price elasticity is -0.41 [9].

${ }^{4}$ Which outcome occurs depends on the shape of the indifference curves relative to the budget set; this is represented by the three alternative indifference curves in Figure 2. Because, as modeled below, water is an essential good, we can rule out the possibility that consumption occurs at the corner solution of zero consumption. Under decreasingblock structures, budget sets are non-convex, enabling multiple tangencies between indifference curves and the budget constraint. The theory and empirics of the non-convex case are straightforward extensions of the convex case, and they have been developed generally [10], [11]; for labor supply [12], [13]; and for water demand [14],
} 
Price elasticity under IBPs is typically modeled as the change in demand that results from a one percent change in all marginal prices at once. ${ }^{5}$ Some of the largest price elasticity estimates, in the range of -1 to -2 , have been obtained with structural analyses that model directly the piecewise-linear budget constraint created by block pricing [15], [16], drawing upon an approach developed to estimate labor supply effects of progressive income taxation. ${ }^{6}$ In addition, two meta-analyses have found that elasticity estimates where IBPs are implemented are higher than estimates of elasticity under linear marginal prices [8], [9]. In comparing elasticities across different studies, the meta-analyses face many confounding factors that differentiate the studies in their samples. They control for some, but not all, of these factors. Another analysis at the utility, rather than the household level, suggests that demand is more elastic under IBPs than under decreasing block structures [20]. Results like these have caused some conjecture that previous elasticity estimates were biased, since they had not accounted for piecewise-linearity, or that IBPs themselves are responsible for greater sensitivity of demand to price [9], [8], [20].

Differences in elasticity estimates across price structures may arise from many sources. First, price elasticity as a mathematical measure captures something different under uniform and IBP structures. A price elasticity under IBPs includes two components absent from price elasticity under a constant marginal price - the elasticities of the probabilities that a household

[15].

${ }^{5}$ The alternative is to consider the demand response to a change in just one of the block prices. However, considering a change in all of the block prices is more intuitive because then, no matter what marginal price a consumer faces, she experiences a one percent price increase on the margin. For consumers in the upper tiers of an IBP, the resulting changes in infra-marginal prices can be "rebated" by subtracting increased infra-marginal expenditures from household income. We discuss this further in Section 2.3.

${ }^{6}$ Prior to Hewitt and Hanemann (1995), only three published studies had estimated price elasticities in the elastic range [17], [18], [19]. 
will locate at each possible kink or segment along its budget constraint, and the response of infra-marginal subsidies to price changes, essentially a secondary income effect. ${ }^{7}$ In the Appendix, we derive a mathematical expression for price elasticity under IBPs and contrast this with elasticity under uniform prices. We show that structural IBP elasticity estimates that account for these extra components of the demand response to price changes may be either lower or higher than estimates of elasticity conditional on consumers remaining within their current blocks. Thus, while differences may arise from the correct estimation of an unconditional IBP elasticity, this cannot explain a priori why elasticity estimates under IBPs tend to be higher than those under uniform prices.

Are there other potential explanations? Intuitively, IBPs introduce at least one threshold beyond which consumption causes an increase in the marginal water price, thus they may simply make prices more salient to consumers. Improvements in the presentation of water price information on water bills has been shown to increase consumers' price responsiveness, and IBPs may provide a similar signal [21]. Behavioral reactions to non-linear prices have been observed in the context of government tax and transfer programs [22].

\section{Demand Models}

The structural discrete/continuous choice (DCC) model was developed in the study of labor supply by Hausman [12], [13] and generalized by Moffitt [10], [11]. The theoretically similar context implied by discrete/continuous consumption problems was developed by Hanemann [23], and first applied to water demand by Hewitt [14].

\footnotetext{
${ }^{7}$ This secondary income effect is due to "virtual income," a concept introduced in detail in Section 3.
} 
In the present analysis, we use a log-log demand function, described by (1). ${ }^{8}$

$$
\ln w=Z \delta+\alpha \ln p+\gamma \ln y+\eta+\varepsilon
$$

The dependent variable is the log of daily household water demand. The marginal price of water is $p$, and income is $y$. Water demand, with the exception of the small fraction used for drinking, is derived demand in which the primary demand is for water-consuming goods and services, such as clean laundry, indoor bathroom use, and green lawns. Thus, in addition to price and income, the demand models also include household characteristics. These variables, as well as daily weather observations and city fixed effects, are included in the matrix $Z$. The model has two error terms. The first source of error $(\eta)$ represents heterogeneous water consumption preferences among households not explained by the household characteristics in $Z$. The second source of error $(\varepsilon)$ reflects random error unobservable to both the household and the analyst. From the household's perspective, actual use may not coincide with optimal use due to leaks or other causes. From the analyst's perspective, $\varepsilon$ captures these optimization errors, as well as the usual measurement error. We assume that the two errors are independent and normally distributed with mean zero and variances $\sigma_{\eta}^{2}$ and $\sigma_{\varepsilon}^{2}$

If all households face uniform prices for water (i.e., the price does not vary with quantity consumed), the demand function in (1) combined with normal error terms yields a conventional log-likelihood function for a log-normal regression (2), where $w$ is observed consumption and $w^{*}($.$) is optimal consumption. Maximizing (2) would produce parameter estimates equal to$ ordinary least squares (OLS) estimates.

\footnotetext{
${ }^{8}$ This functional form is common in water demand analysis, due in part to the typically extreme right-skewness of demand. We use it here to be able to compare our estimates with other DCC models [15], [24].
} 


$$
\begin{aligned}
& \ln L=\sum \ln \left(\frac{1}{\sqrt{2 \pi}} * \frac{\exp \left(-(s)^{2} / 2\right)}{\sigma_{v}}\right) \\
& \text { Where: } \begin{array}{l}
v=\eta+\varepsilon \\
s=\left(\ln w-\ln w^{*}(Z, p, y ; \delta, \alpha, \gamma)\right) / \sigma_{v}
\end{array}
\end{aligned}
$$

However, with increasing block prices, demand becomes more complicated. With $K$ blocks, each with block price $p_{k}$, the blocks are separated by $K-1$ switching points or "kinks" denoted $w_{k}$. There is now a key distinction between conditional demand functions and the unconditional demand function. Conditional demand is defined as the quantity the individual consumes conditional on the fact that her consumption is in the $k^{\text {th }}$ price block. This is simply given by the demand function in (1) evaluated at the marginal price $p_{k}$ and income equal to $\tilde{y}_{k}=y+d_{k}$,

where:

$$
d_{k}=\left\{\begin{array}{l}
0 \text { if } k=1 \\
\sum_{j=1}^{k-1}\left(p_{j+1}-p_{j}\right) w_{k} \text { if } k>1
\end{array}\right.
$$

For households consuming anywhere beyond the first block, there is a wedge between the marginal and average price of water. The implicit subsidy from the infra-marginal rates is accounted for by adding to income the difference, $d_{k}$, between what a household would pay if all units were charged at the marginal price, and what they actually pay. This income supplement for a household consuming in the second block of a two-tier price structure would be equal to the 
shaded region in Figure 1. 9 The sum of income and $d_{k}$ is commonly called "virtual income," here denoted $\tilde{y}_{k}$. There is a separate conditional demand function for each block. By contrast, there is but a single unconditional demand function, and this characterizes the consumer's overall choice - not just how much to consume conditional on being in a given price block, but also which price block to choose. ${ }^{10}$

Take, for example, a household's choice when $K=2$, and $x$ is consumption of all goods other than water (Figure 2). If a household's demand for water, conditional on being in block 1, is less than the kink point $w_{l}$, then this is also its unconditional demand, and the household will consume in the first block (e.g., curve A). If conditional demand associated with block 2 exceeds $w_{1}$, then unconditional demand coincides with the conditional demand for block 2 , and the household will consume in the second block (curve B). There is also the possibility that the household might consume exactly at the kink point, $w_{l}$ (curve C). This occurs if both the conditional demand function for block 1 yields a demand larger than $w_{l}$ and the conditional demand function for block 2 yields demand smaller than $w_{1}$. In that case, the unconditional demand is $w_{1}$, adjusting for random error $(\varepsilon)$. Such households would like to locate on either of the dotted lines extending the two budget segments from the kink point in Figure 2, but these choices are simply not available to them. All of this is captured by (4), unconditional demand, a function of conditional demands and kink points, where $w$ is observed consumption, $\underline{w}_{k}^{*}\left(Z, p_{k}, \tilde{y}_{k} ; \delta, \alpha, \gamma\right)$ is optimal consumption on block $k$, and $w_{k}$ is consumption at kink point $k$.

\footnotetext{
${ }^{9}$ The treatment of infra-marginal price changes as lump-sum changes in household income was developed in the labor supply literature [25], [12], and the electricity demand literature [26], [27]. The first application to water demand was by Billings and Agthe [28].

${ }^{10} \mathrm{With}$ uniform prices, by contrast, the unconditional demand function is given by (1) directly.
} 


$$
\ln w=\left\{\begin{array}{l}
\ln \underline{w}_{1}^{*}\left(Z, p_{1}, \tilde{y}_{1} ; \delta, \alpha, \gamma\right)+\eta+\varepsilon \\
\quad \text { if }-\infty<\eta<\ln w_{1}-\ln \underline{w}_{1}^{*}\left(Z, p_{1}, \tilde{y}_{1} ; \delta, \alpha, \gamma\right) \\
\ln w_{1}+\varepsilon \\
\quad \text { if } \ln w_{1}-\ln \underline{w}_{1}^{*}\left(Z, p_{1}, \tilde{y}_{1} ; \delta, \alpha, \gamma\right)<\eta<\ln w_{1}-\ln \underline{w}_{2}^{*}\left(Z, p_{2}, \tilde{y}_{2} ; \delta, \alpha, \gamma\right) \\
\ln \underline{w}_{2}^{*}\left(Z, p_{2}, \tilde{y}_{2} ; \delta, \alpha, \gamma\right)+\eta+\varepsilon \\
\quad \text { if } \ln w_{1}-\ln \underline{w}_{2}^{*}\left(Z, p_{2}, \tilde{y}_{2} ; \delta, \alpha, \gamma\right)<\eta<\ln w_{2}-\ln \underline{w}_{2}^{*}\left(Z, p_{2}, \tilde{y}_{2} ; \delta, \alpha, \gamma\right) \\
\ldots \quad \text { if } \ln w_{K-1}-\ln \underline{w}_{K-1}^{*}\left(Z, p_{K-1}, \tilde{y}_{K-1} ; \delta, \alpha, \gamma\right)<\eta<\ln w_{K-1}-\ln \underline{w}_{K}^{*}\left(Z, p_{K}, \tilde{y}_{K} ; \delta, \alpha, \gamma\right) \\
\ln w_{K-1}+\varepsilon \\
\quad \text { if } \ln \underline{w}_{K-1}^{*}\left(Z, p_{K}, \tilde{y}_{K} ; \delta, \alpha, \gamma\right)+\eta+\varepsilon \\
\quad \underline{w}_{K}^{*}\left(Z, p_{K}, \tilde{y}_{K} ; \delta, \alpha, \gamma\right)<\eta<\infty
\end{array}\right.
$$

Given the simultaneous determination of consumption and block price, if a typical single-error stochastic specification were employed, the size of the error term, marginal price, and virtual income would be systematically correlated. Thus, OLS estimates of the demand parameters will be biased and inconsistent. In the literature, this problem has been addressed with instrumental variables (IV) models, such as two-stage least squares, for labor supply and water and energy demand [29], [30], [19], [31], [32]. While such models can estimate downward-sloping demand curves, they exhibit two key limitations. First, simultaneous equations models can be used only to estimate elasticities conditional on remaining within the observed consumption block. Second, IV methods disregard the fact that some households consume within the neighborhood of a kink point, where it is unclear which value of marginal price should be assigned (in an econometric model that includes one or more error terms). Arbitrary treatment of these observations, such as assigning them to one block or another or dropping them from the sample, cannot be reconciled with utility theory. The DCC model, a 
maximum likelihood model, addresses these issues. The log-likelihood function for $K>1$ is given by (5), in which $\Phi$ is the standard normal cumulative distribution function. ${ }^{11}$ The first summation accounts for consumption along $K$ linear budget segments, and the second summation for consumption at $K-1$ kinks.

$$
\begin{aligned}
& \ln L=\sum \ln \left[\begin{array}{l}
\sum_{k=1}^{K}\left(\frac{1}{\sqrt{2 \pi}} * \frac{\exp \left(-\left(s_{k}\right)^{2} / 2\right)}{\sigma_{v}}\right) *\left(\Phi\left(r_{k}\right)-\Phi\left(n_{k}\right)\right) \\
+\sum_{k=1}^{K-1}\left(\frac{1}{\sqrt{2 \pi}} * \frac{\exp \left(-\left(u_{k}\right)^{2} / 2\right)}{\sigma_{\varepsilon}}\right) *\left(\Phi\left(m_{k}\right)-\Phi\left(t_{k}\right)\right)
\end{array}\right] \\
& v=\eta+\varepsilon \\
& t_{k}=\left(\ln w_{k}-\ln \underline{w}_{k}^{*}(.)\right) / \sigma_{\eta} \\
& \text { Where: } \rho=\operatorname{corr}(v, \eta) \quad r_{k}=\left(t_{k}-\rho s_{k}\right) / \sqrt{1-\rho^{2}} \\
& s_{k}=\left(\ln w_{i}-\ln \underline{w}_{k}^{*}(.)\right) / \sigma_{v} \quad m_{k}=\left(\ln w_{k}-\ln \underline{w}_{k+1}^{*}(.)\right) / \sigma_{\eta} \\
& u_{k}=\left(\ln w_{i}-\ln w_{k}\right) / \sigma_{\varepsilon} \quad n_{k}=\left(m_{k-1}-\rho s_{k}\right) / \sqrt{1-\rho^{2}}
\end{aligned}
$$

The estimated parameters can be used to calculate the expected unconditional demand and to measure the price elasticity of demand. In the Appendix, we provide analytical formulas for the expected unconditional demand and the price elasticity of demand. The overall price elasticity of demand is defined with respect to an equi-proportional change in all block prices. ${ }^{12}$

\footnotetext{
${ }^{11}$ The derivation of the IBP portion of the likelihood function is described in [33].

${ }^{12}$ In the empirical analysis below, the elasticity is estimated by imposing a one percent change in each block price and numerically calculating the resulting percentage change in expected unconditional demand.
} 


\section{THE DATA}

The data comprise 1,082 households in 11 urban areas in the United States and Canada, served by 16 public water utilities. ${ }^{13}$ Table 1 provides descriptive statistics.

Daily household water demand and weather conditions are observed over two weeks in an arid season and two weeks in a wet season. Daily demand data were gathered by automated data loggers, attached to household water meters by utility staff. Households move seasonally across price blocks. During the wet season, for example, among households facing two-tier IBPs, 56 percent of household-days are observed in the first block, and 44 percent in the second. During the dry season, first-block observations are 25 percent of the total, and second-block 75 percent. ${ }^{14}$ Given the econometric similarities between our analysis of water demand and labor supply analysis under progressive income taxation, it is interesting to discuss the degree to which consumers "cluster" at kink points. Among households facing IBPs in our data, approximately 40 percent of demand observations lie within 5 percent of a kink point (from above or below).

Each household faces one price structure throughout a season, but some price structures change between the two seasons. Thus, the data include 26 price structures: 8 two-tier IBP structures, 10 four-tier IBP structures, and 8 uniform structures. Marginal prices range from $\$ 0$ to $\$ 4.96$ per thousand gallons (kgal), with a mean of $\$ 1.71 / \mathrm{kgal}$. Assuming that the four weeks

\footnotetext{
${ }^{13}$ The data were gathered by Mayer et al. [34] for a study sponsored by the American Waterworks Association Research Foundation. Sample utilities include Denver Water (CO); Eugene Water and Electric Board (OR); Seattle Public Utilities (WA); City of Bellevue Utilities Department (WA); Highline Water District (WA); Northshore Utility District (WA); City of San Diego Water Department (CA); Tampa Water Department (FL); Phoenix Water Department (AZ); City of Tempe Water Utilities (AZ); City of Scottsdale Water Department (AZ); Regional Water Services, Municipality of Waterloo (ONT); City of Cambridge (ONT); Walnut Valley Water District (CA); City of Lompoc Utilities Department (CA); and Las Virgenes Municipal Water District (CA).

${ }^{14}$ Similar movement can be seen for households facing four-tier IBPs. The share of household-days observed in the first block among 4-tier households is 37 percent in the wet season, and 18 percent in the dry season; third-block observations comprise 24 percent of household-days in the wet season, and 62 percent in the dry season.
} 
of water demand we observe are representative of annual patterns, the total average annual household expenditure on water in this sample, including fixed charges, would be about $\$ 327$.

Household demographic data were collected by survey. ${ }^{15}$ These include lot size, square footage of homes, number of bathrooms, and family size. Home age is also included in the water demand equation, and we expect that both very old and new homes may use less water than "middle aged" homes. ${ }^{16}$ We also control for the presence or absence of evaporative cooling, which substitutes water for electricity in air conditioning. ${ }^{17}$

We include a set of daily weather variables. Maximum daily temperature is represented by maxt, weath represents the moisture requirements of green lawns not met by precipitation, and seas is a dummy variable set equal to one during the arid (peak outdoor watering) season. ${ }^{18}$ Finally, the models include a set of dummy variables that represent the 11 urban areas included in the study: Denver, Eugene, Seattle, San Diego, Tampa, Phoenix, Tempe/Scottsdale, Waterloo/Cambridge (Ontario), Walnut Valley, Las Virgenes, and Lompoc, accounting for variations in geography and other factors not addressed by the other covariates.

\footnotetext{
${ }^{15}$ Households chosen for the study were randomly sampled from a subset of utilities' customer databases: singlefamily households. Sampling procedures, response rates, and statistical tests for selection bias are described in [34].

${ }^{16}$ Very old homes are likely to have smaller connections to their city water system, and also fewer water-using appliances, such as dishwashers and jacuzzis, than do newer homes. The newest homes were built after the passage of local ordinances in the 1980s and 1990s requiring water-conserving toilets and showers.

${ }^{17}$ In our sample, households with evaporative coolers use on average 40 percent more water per day. We include this variable to avoid biasing the other parameter estimates, particularly the income coefficient estimate, since evaporative cooling is relatively more common in low-income households.

${ }^{18}$ Lawn moisture needs are captured through estimated evapotranspiration (ET), less effective rainfall (equal to $0.6 *$ measured precipitation). We use Hargreaves' approximation to the Penman-Monteith evapotranspiration equation, which requires mean, minimum, and maximum daily temperature, degrees latitude (to estimate a solar radiation parameter), and a readily-available constant associated with the "crop" of interest - grass.
} 


\section{EMPIRICAL RESULTS}

The full-sample DCC model, with the likelihood function the sum of (2) for uniformprice households and (5) for IBP households, is our baseline model. We explore the possibility of variation in price elasticity with price structure by estimating two further demand models: the baseline DCC model, but for IBP households only; and a panel random-effects model for uniform price (UP) households only. We then perform some additional analysis regarding the possibility of endogenous price structures.

\subsection{Full-Sample Discrete/Continuous Choice Model}

Table 2 reports results of the full-sample DCC model in column 1. The DCC parameter estimates amount to elasticities conditional on block location. Table 3 reports the means and standard deviations of unconditional elasticity estimates bootstrapped parametrically and nonparametrically. These unconditional elasticities include the impacts of price changes on the probability of block and/or kink switching. ${ }^{19}$

The parameter of greatest interest, price elasticity, indicates that a one percent price increase will reduce demand by 0.33 percent, all else equal. ${ }^{20}$ Our simulated price elasticity, produced by exploiting the widest variation yet available in price, price structure, and individual household characteristics, is comparable to the central tendency of estimates over the past 40

\footnotetext{
${ }^{19}$ For the non-parametric simulations, we draw 100 random samples of size N, with replacement, from the data; take the expectation of conditional demand in exponential form; simulate a one percent change in price or income; calculate the resulting percent change in expected demand; and report the mean of bootstrapped estimates. For the parametric simulations, we generate 100 random draws from each error distribution and estimate elasticities for each pair of error draws, using the original data and parameter estimates and taking expectations of conditional demand.

${ }^{20}$ Recall that price elasticity in our DCC models is a percent change in quantity demanded for a one percent increase in all prices in a household's price structure, including the impact on virtual income of increases in infra-marginal prices. Our elasticity estimates are a mixture of short-run and long-run. Much of the variation in price comes from the cross-section. But there is also substantial variation within individual households over time, due to IBPs. There is also a small amount of variation in price over time due to utility price changes.
} 
years, but much lower than those previously estimated using the DCC approach with smaller, more restrictive samples. ${ }^{21}$ Hewitt and Hanemann, for example, obtain an elasticity almost six times the magnitude of ours [15]. Note that the simulated unconditional elasticity estimate is smaller in absolute value than the price parameter estimate, the conditional elasticity. ${ }^{22}$ In this sample, block-switching dampens the price elasticity, though it need not have done so in theory, as we show in the Appendix.

There are two intuitive reasons for this dampening effect. First, households may stick at kink points, where their price elasticity is zero. Second, if the price falls, and optimal consumption increases enough to move the household to a higher block, movement across the kink point immediately results in a marginal price increase (to the price of the new block), dampening the increase in demand we might expect from the original price decrease. The same would be true for a price increase, which might push the household into a lower block, at which it suddenly faces a lower marginal price. In our sample, these two effects seem to dominate any potential influences that, mathematically, could push this difference in the other direction. ${ }^{23}$

Weather, income and the other household-level characteristics affect demand in expected ways. Results regarding home age are weak, but as expected. The highest water demand occurs

\footnotetext{
${ }^{21}$ As a point of reference, we also estimated a random effects model for the full sample to demonstrate the price endogeneity problem. The estimated price elasticity is 1.40 , reflecting upward-sloping price schedules, not upwardsloping demand.

${ }^{22}$ This is true of Hewitt and Hanemann, as well - simulated elasticities, allowing block-switching, are smaller than price coefficient estimates [15].

${ }^{23}$ In general, these include both virtual income effects (which unambiguously raise the unconditional price elasticity, relative to the conditional elasticity), and the impact of price changes on the probabilities of the household's location on each segment and kink in its budget constraint (which might work in either direction). See the Appendix for a careful discussion of these effects.
} 
among homes aged 20 to 40 years; both newer homes and older homes use less water. ${ }^{24}$ Our income elasticity estimate $(0.13)$ is low compared with previous studies, usually between 0.2 and 0.6 [4]. Few previous studies have included household-level housing characteristics, which are strongly correlated with income. Their omission may have overestimated the influence of income on water demand. ${ }^{25}$ Maximization of the likelihood function also provides estimates of $\sigma_{\eta}$ and $\sigma_{\varepsilon^{*}}$ Consistent with the tax literature, household heterogeneity is responsible for more of the observed variation in water demand than random error.

\subsection{Exploring Elasticity Magnitude and Price Structure}

When we estimate the DCC model for households facing IBPs only, we obtain a simulated price elasticity of approximately -0.59 . When we estimate a panel random-effects model for households facing uniform marginal prices only, we obtain an elasticity estimate of -0.33 , and the estimate is statistically insignificant, even with about 400 households in this group. This pattern reflects what we see in the existing literature, even though the 95 percent confidence intervals for these two estimates overlap, as the UP estimate is noisy. In comparisons of studies using different samples, we observe more elastic demand among block-price samples than among uniform-price samples. The observed differences are much more significant than the small differences between our DCC price coefficients and elasticity estimates, which can be

\footnotetext{
${ }^{24} \mathrm{We}$ have also estimated a model replacing the quadratic home age specification with the following home age categories: pre-1960; 1960-69; 1970-79; 1980-89; and 1990-96. Results are qualitatively similar. All else equal, water consumption peaks among homes built between 1970 and 1979. Both newer and older homes use less water. There were no significant changes to the other demand parameters in this alternative model.

${ }^{25}$ If we estimate our DCC model omitting all household characteristics, except income, we obtain an income elasticity of 0.32 .
} 
accounted for by block-switching. Does price elasticity vary with price structure, all else equal, or is something else going on?

\subsubsection{Tests of simple theoretical explanations}

To examine the relationship between price elasticity and price structure, we investigate whether the observed difference can be explained by theory. First, we would expect price elasticities to be larger in the long run than in the short run. It is possible that this explains the differences seen in the previous literature. It does not explain the difference we see in our data, since all households (IBP and UP) were observed over approximately the same time period.

Second, if the average magnitude of prices were higher in IBP cities than in uniformprice cities, this could explain the observed difference in the magnitude of price elasticity. In our sample, the average magnitude of marginal price in uniform-price cities is $\$ 1.72$ per kgal, while in block-price cities it is $\$ 1.78$ (assuming that marginal price for IBP households is price in the block of observed consumption). With a difference this small, it is unlikely that heterogeneity in the average magnitude of prices is responsible for the difference in elasticities we observe.

Third, if the percentage of total income devoted to water consumption were lower among households in uniform price cities, on average, than among households facing IBPs, this might explain the observed difference in elasticities. Estimated annual expenditures on water consumption (including fixed charges) in our sample are approximately 0.5 percent of annual income; the budget share for water does not differ significantly across price structures.

We have eliminated some likely candidates from the list of potential explanations for variation in price elasticity with price structure. Two possibilities remain. First, it is conceivable that part of the observed difference in price elasticity of demand across price 
structures is driven by the shape of price structures. But correlation does not demonstrate causality. The second possibility is that price structures, themselves, are endogenous.

\subsubsection{The possibility of endogenous price structures at the utility level}

Our concern is that some unobserved characteristic of households within a community drives a utility's choice of price structure, and that this characteristic may be correlated with price elasticity. For example, environmentally conscious households may pay more attention to water prices, resulting in higher elasticity, and relatively "green" communities may also be more likely to adopt IBPs, seen as conservation tools. Conversely, communities facing long-term aridity and long growing seasons may lead utilities to adopt IBPs; these same communities may be places in which households place a high premium on outdoor water consumption and are thus less price sensitive. ${ }^{26}$ The significant differences in coefficient estimates in columns 2 and 3 of Table 2 support the possibility of unobserved heterogeneity across UP and IBP households that may be correlated with water demand.

Ideally, to test for the possibility of endogenous price structures, we would estimate a two-stage model, first predicting price structure at the utility level, then estimating elasticity, given the predicted price structure. With the appropriate choice of instruments, this would presumably give us unbiased estimates of price elasticity, free of the effects of underlying heterogeneity in price structure choice among utilities. However, the data include only 16 water utilities, a sample too small to support the first stage of such a selection model.

We take a second-best approach. We test our full-sample models, allowing the price elasticity parameter to vary with price structure, but constraining the remaining demand

\footnotetext{
${ }^{26}$ For estimates of low price elasticity among households with strong preferences for outdoor consumption, see [35].
} 
parameters to be equal. It is likely that our model includes some endogenous variation in price structure choice. However, our data are the best known to us for this purpose, thus we perform what should be considered, at best, an informal test. In addition, the amount of price variation within uniform price cities, alone, is very small - the reason we were unable to estimate a statistically significant elasticity for those cities in our split-sample models. ${ }^{27}$ Results, reported in the fourth column of Table 2, should be interpreted with these caveats in mind.

Like the split-sample models, the model with a block pricing/price interaction term suggests that demand among IBP households is more elastic than among UP households. The other demand parameters are essentially unchanged, with the exception of some of the city fixed effects - not surprising, as the block-pricing interaction may now be accounting for some of the variation absorbed by city fixed effects in prior models.

These results do not rule out the possibility of a behavioral reaction to the structure of water prices, due to increased attention to price or any other factor. However, given our remaining selection concerns, we cannot say definitively that IBPs tend to increase elasticity. We cannot dismiss the hypothesis that underlying city-level heterogeneity in characteristics such as aridity and conservation programs, which may be correlated with both consumers' price elasticity and utilities' price schedule choice, explains part of the observed pattern in the literature of higher price elasticity under IBPs.

\section{CONCLuSION}

\footnotetext{
${ }^{27}$ Taking into account the variation over time and space, we have 13 uniform price observations. Variation in block prices (both across utilities and within the individual price structures, themselves) is much more extensive.
} 
This paper considers both aspects of the separation of demand and supply under non-linear pricing - simultaneous choice of price block and quantity consumed at the household level, and endogenous price structure at the utility level. We estimate the price elasticity of water demand among urban households facing increasing block and uniform marginal prices, using a structural DCC model that accommodates piecewise-linear budget constraints. Previous estimates of the price elasticity of water demand using DCC models have been very high relative to the central tendency of estimates in the literature using other models. Our estimates, which exploit a broadly representative and highly detailed sample of North American single-family households are much closer to the central tendency of prior estimates. While the DCC model is theoretically the appropriate model for estimating elasticities under IBPs, our results suggest that these models may not induce a significant break in how we think about consumer responses to non-linear water prices, as they did when introduced in the literature on the wage elasticity of labor supply under progressive income taxation.

That said, an additional lesson of the analysis is that elasticity under IBPs measures an inherently different phenomenon than elasticity under linear marginal prices. In the Appendix, we develop an expression for what is captured by an unconditional price elasticity under IBPs, and compare our conditional and unconditional estimates on this basis. While the differences between conditional and unconditional elasticities of water demand may not be economically significant in our case, non-linear prices are present in many other markets (e.g., cellular phone service, electricity), and an understanding of what an elasticity is measuring is critical, especially in regulated markets in which price is an important policy lever (for example, a tool to promote energy conservation). 
Finally, in response to a literature that suggests that price elasticity varies with the shape of administratively-determined supply curves, in ways unconnected to the mathematical difference between price elasticity under different price structures, we estimate separate price elasticities for two sub-samples of households - those facing IBPs and those facing uniform marginal prices. The elasticities do appear to differ (indeed, we fail to identify a price elasticity significantly different from zero for the uniform-price households, alone), and we are able to eliminate a number of simple explanations that would be consistent with economic theory. In a second full sample model, allowing price elasticity to vary with price structure and constraining all other demand parameters to be equal, we again observe a greater price elasticity under IBPs. Neither of these tests accounts for selection on price structure at the utility level. Thus, while the possibility of a behavioral response to price structure cannot be ruled out, neither can we definitively identify such an effect. The collection of data suitable for estimating a two-stage model of water demand under endogenous price structures would be a productive area for future research.

Regardless of their potential implications for price elasticity, an important efficiency justification for the implementation of IBPs remains. To the extent that IBPs increase the portion of consumers facing efficient prices for a scarce resource on the margin, they may well be welfare-improving (and environmentally beneficial at the same time). Exploration of the efficiency advantages of IBPs is another area for further research. 


\section{Appendix. How Price Affects Demand with Increasing Block Prices}

In the presence of increasing block prices (IBPs), the concept of how price affects demand is, itself, somewhat elusive: since there are multiple prices corresponding to the multiple rate blocks, which price is being considered? Does one consider a single block price or all block prices? If all prices are considered, how is the response of demand to an across-the board change in all prices with an IBP different from the response of demand to a change in a conventional flat-rate price? In this Appendix we answer some of these questions. Since the results may be of some general interest, we start with a general model of demand with multiplicative random terms, deriving some general results regarding IBPs. We then specialize the results to the log$\log$ functional form in (1).

We use the following notation for a general model of demand. The general conditional demand function with multiplicative random terms is written as (A1):

$$
w=w\left(p_{k}, y+d_{k}\right) e^{\varepsilon} e^{\eta}
$$

where $\varepsilon$ and $\eta$ are independently normally distributed with zero mean and variances $\sigma_{\varepsilon}^{2}$ and

$\sigma_{\eta}^{2}$. Recall that $w_{k}$ denotes the switching point between blocks $k$ and $k+1$, and $w\left(p_{k}, y+d_{k}\right) e^{\varepsilon} e^{\eta} \quad$ is consumption within the $k^{\text {th }}$ block. Define: 


$$
\begin{aligned}
& a_{k} \equiv w_{k-1} / w\left(p_{k}, y+d_{k}\right) \\
& b_{k} \equiv w_{k} / w\left(p_{k}, y+d_{k}\right) \\
& c_{k} \equiv w_{k} / w\left(p_{k+1}, y+d_{k+1}\right)
\end{aligned}
$$

In the presence of an IBP schedule with $K$ blocks (and $K-1$ switching points), the utilitymaximizing consumer ends up either somewhere along a block or at one of the switching points.

Let $\pi_{k}$ denote the probability that the consumer chooses some quantity within the $k^{\text {th }}$ block, and

let $\lambda_{k}$ denote the probability that the consumer chooses to locate at the switching point $w_{k}$. Then:

$$
\begin{array}{ll}
\pi_{k}=\Phi\left(\frac{\ln b_{k}}{\sigma_{\eta}}\right)-\Phi\left(\frac{\ln a_{k}}{\sigma_{\eta}}\right) & k=(1, \ldots, K) \\
\lambda_{k}=\Phi\left(\frac{\ln c_{k}}{\sigma_{\eta}}\right)-\Phi\left(\frac{\ln b_{k}}{\sigma_{\eta}}\right) & k=(1, \ldots, K-1)
\end{array}
$$

where $\Phi$ is the standard normal cumulative distribution function. Observe that:

$$
\sum_{k=1}^{K} \pi_{k}+\sum_{k=1}^{K-1} \lambda_{k}=1
$$

For a moment, leave the distribution of $\eta$ unspecified. With the multiplicative random terms, the expected quantity demanded by the consumer in the face of IBPs - the mean of the unconditional demand function (denoted $W$ ) - takes the form:

$$
W=\left[\sum_{k=1}^{K} w\left(p_{k}, y+d_{k}\right) e^{\sigma_{\varepsilon}^{2} / 2} * \int_{a_{k}}^{b_{k}} \xi f(\xi) d \xi\right]+\sum_{k=1}^{K-1} w_{k} e^{\sigma_{\varepsilon}^{2} / 2} \lambda_{k}
$$


where $\xi=e^{\eta}$; the term with the integral is the partial mean of $\xi$ over the interval $\left[a_{k}, b_{k}\right]$. When $\eta$ is normal, making $\xi$ lognormal, the formula reduces to:

$$
W=\left[\sum_{k=1}^{K} w\left(p_{k}, y+d_{k}\right) e^{\sigma_{\varepsilon}^{2} / 2} \pi_{k}^{*}\right]+\sum_{k=1}^{K-1} w_{k} e^{\sigma_{\varepsilon}^{2} / 2} \lambda_{k}
$$

where:

$$
\pi_{k}^{*}=\Phi\left(\frac{\ln b_{k}}{\sigma_{\eta}}-\sigma_{\eta}\right)-\Phi\left(\frac{\ln a_{k}}{\sigma_{\eta}}-\sigma_{\eta}\right)
$$

It follows from (A6) that expected unconditional demand depends on the block prices in a complex manner. By way of illustration, suppose there is a reduction in the price of the second block, $p_{2}$. This affects the consumer's demand in several different ways. Not surprisingly, the change in $p_{2}$ has no effect on consumption in the first block, $d w\left(p_{1}, y\right) / d p_{2}=0$, or on the probability of being in that block, $d \pi_{1} / d p_{2}=0$. However, it does affect demand in all other blocks. If the consumer is located in the second block and stays there, his demand changes not only because of the price reduction but also because the change in $p_{2}$ causes the income adjustment term $d_{2}$ to change: $\partial d_{2} / \partial p_{2}=w_{1}$. The total impact on consumption within the second block is:

$$
d w\left(p_{2}, y+d_{2}\right) / d p_{2}=\partial w\left(p_{2}, y+d_{2}\right) / \partial p_{2}+w_{1} \partial w\left(p_{2}, y+d_{2}\right) / \partial y
$$


If the commodity is a normal good with a non-negative income effect, this total derivative is negative ${ }^{28}$ hence, consumption in the second block unambiguously increases.

The price reduction unambiguously reduces the probability of being at the switching point at the low end of the second block, $w_{1}$, since:

$$
\frac{d \lambda_{1}}{d p_{2}}=-\frac{\phi\left(c_{1}\right)}{\sigma_{\eta} w\left(p_{2}, y+d_{2}\right)} \frac{d w\left(p_{2}, y+d_{2}\right)}{d p_{2}}>0
$$

where $\phi($.$) is the standard unit normal PDF. However, some of the other effects are ambiguous.$

Starting with the probability of being in the second block,

$$
\frac{d \pi_{2}}{d p_{2}}=\frac{1}{\sigma_{\eta} w\left(p_{2}, y+d_{2}\right)} \frac{d w\left(p_{2}, y+d_{2}\right)}{d p_{2}}\left[\phi\left(\ln a_{2} / \sigma_{\eta}\right)-\phi\left(\ln b_{2} / \sigma_{\eta}\right)\right]
$$

Since $d w\left(p_{2}, y+d_{2}\right) / d p_{2}<0$, and since the standard unit normal PDF is symmetric and unimodal with a mode of zero, one obtains:

$$
\frac{d \pi_{2}}{d p_{2}} \geq(\leq) 0 \quad \text { as } \quad w_{1} w_{2} \leq(\geq) w\left(p_{2}, y+d_{2}\right)^{2}
$$

The effect of the price change can go either way because, while the lower price in block 2 encourages the consumer to use more in that block, it may also push him into a higher consumption block. Similarly, with the probability of being at the switchpoint $w_{2}$,

$\begin{aligned} 0 & \geq \partial w\left(p_{2}, y+d_{2}\right) / \partial p_{2}+w\left(p_{2}, y+d_{2}\right) \partial w\left(p_{2}, y+d_{2}\right) / \partial y \\ & \geq \partial w\left(p_{2}, y+d_{2}\right) / \partial p_{2}+w_{1} \partial w\left(p_{2}, y+d_{2}\right) / \partial y\end{aligned}$. 


$$
\begin{aligned}
& \frac{d \lambda_{2}}{d p_{2}}=\frac{1}{\sigma_{\eta} w\left(p_{2}, y+d_{2}\right)} * \\
& {\left[\phi\left(\frac{\ln c_{2}}{\sigma_{\eta}}\right) \frac{d w\left(p_{2}, y+d_{2}\right)}{d p_{2}}+\left(w_{2}-w_{1}\right) \phi\left(\frac{\ln b_{2}}{\sigma_{\eta}}\right) \frac{w_{2}}{w_{3}} \frac{\partial w\left(p_{3}, y+d_{3}\right)}{\partial y}\right]}
\end{aligned}
$$

Since $\frac{d w\left(p_{2}, y+d_{2}\right)}{d p_{2}}<0$ while $\left(w_{2}-w_{1}\right) \frac{\partial w\left(p_{3}, y+d_{3}\right)}{d y}>0$ and $\frac{w_{2}}{w_{3}}<1$, a complex set of factors determines whether the sign of this derivative is positive (the likelihood of being at the switching point rises) or negative (it falls). For blocks $k>2$,

$$
\begin{aligned}
& \frac{d \lambda_{k}}{d p_{2}}=\frac{1}{\sigma_{\eta} w\left(p_{k+1}, y+d_{k+1}\right)} * \\
& {\left[\phi\left(\frac{\ln c_{k}}{\sigma_{\eta}}\right) \frac{\partial w\left(p_{k+1}, y+d_{k+1}\right)}{\partial y}+\phi\left(\frac{\ln b_{k}}{\sigma_{\eta}}\right) \frac{w_{k+1}}{w_{k}} \frac{\partial w\left(p_{k}, y+d_{k}\right)}{\partial y}\right]}
\end{aligned}
$$

and

$$
\frac{d \pi_{k}}{d p_{2}}=\frac{\left(w_{2}-w_{1}\right)}{\sigma_{\eta} w\left(p_{k}, y+d_{k}\right)} \frac{\partial w\left(p_{k}, y+d_{k}\right)}{\partial y}\left[\phi\left(\frac{\ln b_{k}}{\sigma_{\eta}}\right)-\phi\left(\frac{\ln a_{k}}{\sigma_{\eta}}\right)\right],
$$

where again the sign can be positive or negative.

In some sense, it seems clear that, when the commodity is a normal good and $p_{2}$ decreases, overall consumption unambiguously increases. This is because, from (A4) and the fact that $d \lambda_{1} / d p_{2}>0$, it follows that: 


$$
\frac{d \operatorname{Pr}\left\{\text { consumption } \geq w_{1}\right\}}{d p_{2}}=\frac{d\left[\sum_{k=2}^{K} \pi_{k}+\sum_{k=2}^{K-1} \lambda_{k}\right]}{d p_{2}}<0 .
$$

Moreover, for $\mathrm{k}>2, \frac{d w\left(p_{k}, y+d_{k}\right)}{d p_{2}}=\left(w_{1}-w_{2}\right) \frac{\partial w\left(p_{k}, y+d_{k}\right)}{d y}<0$.

All of these shifts are the responses to a change in a single block price. Things become much more complicated if several block prices change. In order to characterize the overall price elasticity of demand, we proceed as follows. Let $\theta$ be a shift variable which affects all block prices proportionately; the conditional demand functions can now be written $w\left(\theta p_{k}, y+\theta d_{k}\right)$.

The unconditional expected demand can now be viewed as a function of $\theta, W(\theta)$. The overall change in expected demand with respect to a change in $\theta$, evaluated at $\theta=1$, is:

$$
\begin{aligned}
\frac{d W(1)}{d \theta} & =e^{\sigma_{\varepsilon}^{2} / 2}\left[\sum_{k=1}^{K} \frac{d w\left(p_{k}, y+d_{k}\right)}{d \theta} \pi_{k}^{*}+\sum_{k=1}^{K} w\left(p_{k}, y+d_{k}\right) \frac{d \pi_{k}^{*}}{d \theta}+\sum_{k=1}^{K-1} w_{k} \frac{d \lambda_{k}}{d \theta}\right] \\
& =e^{\sigma_{\varepsilon}^{2} / 2}\left[\sum_{k=1}^{K} \frac{d w\left(p_{k}, y+d_{k}\right)}{d \theta}\left\{\pi_{k}^{*}+\frac{\phi\left(\frac{\ln b_{k}}{\sigma_{\eta}}-\sigma_{\eta}\right)-\phi\left(\frac{\ln a_{k}}{\sigma_{\eta}}-\sigma_{\eta}\right)}{\sigma_{\eta}}\right\}+\sum_{k=1}^{K-1} w_{k} \frac{d \lambda_{k}}{d \theta}\right]
\end{aligned}
$$

where the total derivative of conditional demand along a segment with respect to $\theta$ is

$$
\frac{d w\left(p_{k}, y+d_{k}\right)}{d \theta}=\frac{\partial w\left(p_{k}, y+d_{k}\right)}{\partial p_{k}}+d_{k} \frac{\partial w\left(p_{k}, y+d_{k}\right)}{\partial y}
$$

and 


$$
\begin{aligned}
& \frac{d \lambda_{k}}{d \theta}=\frac{1}{\sigma_{\eta} w\left(p_{k}, y+d_{k}\right)} * \\
& {\left[\phi\left(\frac{\ln b_{k}}{\sigma_{\eta}}\right) \frac{d w\left(p_{k}, y+d_{k}\right)}{d \theta}-\frac{w\left(p_{k}, y+d_{k}\right)}{w\left(p_{k+1}, y+d_{k+1}\right)} \phi\left(\frac{\ln a_{k}}{\sigma_{\eta}}\right) \frac{d w\left(p_{k+1}, y+d_{k+1}\right)}{d \theta}\right]^{(\mathrm{A} 19}}
\end{aligned}
$$

In the particular case where the conditional demand function takes the log-log form in (1), with some manipulation (A19) can be written in elasticity form as:

$$
\begin{aligned}
& \frac{1}{W(1)} \frac{d W(1)}{d \theta}= \alpha\left[\sum_{k=1}^{K} \frac{w\left(p_{k}, y+d_{k}\right) \psi_{k}}{p_{k}}+\sum_{k=1}^{K-1} w_{k} \chi_{k}\right] / \Omega+ \\
& \gamma\left[\sum_{k=1}^{K} \frac{w\left(p_{k}, y+d_{k}\right) \psi_{k} d_{k}}{y+d_{k}}+\sum_{k=1}^{K-1} w_{k} \tau_{k}\right] /
\end{aligned}
$$

where $\alpha$ is the price elasticity of demand in the conditional log-log demand function (1) and $\gamma$ is the income elasticity of demand in (1), and:

$$
\begin{aligned}
\psi_{k} & \equiv \pi_{k}^{*}+\frac{1}{\sigma_{\eta}}\left[\phi\left(\frac{\ln b_{k}}{\sigma_{\eta}}-\sigma_{\eta}\right)-\phi\left(\frac{\ln a_{k}}{\sigma_{\eta}}-\sigma_{\eta}\right)\right] \\
\chi_{k} & \equiv \frac{1}{\sigma_{\eta}}\left[\phi\left(\frac{\ln b_{k}}{\sigma_{\eta}}\right) \frac{1}{p_{k}}-\phi\left(\frac{\ln a_{k}}{\sigma_{\eta}}\right) \frac{1}{p_{k+1}}\right] \\
\tau_{k} & \equiv \frac{1}{\sigma_{\eta}}\left[\phi\left(\frac{\ln b_{k}}{\sigma_{\eta}}\right) \frac{d_{k}}{y+d_{k}}-\phi\left(\frac{\ln a_{k}}{\sigma_{\eta}}\right) \frac{d_{k+1}}{y+d_{k+1}}\right] \\
\Omega & \equiv \sum_{k=1}^{K} w\left(p_{k}, y+d_{k}\right) \pi_{k}^{*}+\sum_{k=1}^{K-1} w_{k} \lambda_{k}
\end{aligned}
$$


It follows that overall elasticity of expected demand with respect to $\theta$, namely, $\frac{1}{W(1)} \frac{d W(1)}{d \theta}$, which may be viewed as the analog of the price elasticity of demand for IBP, is a complex combination of both the price and income elasticities of demand associated with the conditional (segment) demand functions. In general, this overall elasticity is different from the simple price elasticity of the conditional demand function, $\alpha$, but it does not appear that either the direction or the magnitude of the difference can be signed in the general case represented by (A20). This is because several factors are involved in the formation of the overall elasticity.

The earlier results for a single block price change, involving (A8) - (A16), can shed some light on these factors. Assume, as before, that the good is a normal good. If $p_{2}$ falls and the consumer still stays in the second block, two things happen. Demand goes up because of the reduced price; but this is tempered by a decrease in demand caused by the decline in the virtual income for that block, $\tilde{y}_{2}$, which is triggered by the reduced differential between $p_{1}$ and $p_{2}$. Assuming there are more than two blocks, the consumer may want to move up out of the second block. Two possibilities need to be considered. (A) One possibility is that the consumer can become "trapped" at the kink point between the second and third blocks. (B) Even if the consumer does succeed in moving into a higher block, two things happen: he faces a higher (unchanged) price, $p_{3}$., but he also experiences a positive income effect from the increase in virtual income, $\tilde{y}_{3}$, caused by the decrease in $p_{2 .}$. While (A) dampens the increase in demand triggered by the reduction in $p_{2}$, (B) could in principle either dampen or amplify it depending on 
the relative strength of the income effect. Recall, also, that the effects on $\pi_{k}$ and $\lambda_{k}$ for $k>1$ are ambiguous.

In the analysis in this paper, we estimate an unconditional price elasticity that is smaller in absolute value than the conditional price elasticity. This suggests that, in our sample, the dampening effects of sticking at kink points and facing higher (lower) prices in a potential new block if prices rise (fall) must outweigh any amplifying effects of changes in virtual income or potential amplifying effects of changes in the probabilities of locating on any particular segment or switch point. This possibility is supported by the fact that the $d_{k}$ are tiny fractions of household income in our case. Hence, the income effect associated with infra-marginal price changes is likely to be very small. This is not necessarily true of other markets characterized by piecewise linear budget constraints. In the case of labor supply, for example, the income effects created by infra-marginal tax rates appear to be very large [36]. With water and electricity, in contrast, the infra-marginal rate subsidies associated with IBPs are found in the literature to have almost no effect because of low prices, small differences between successive price blocks, and the fact that annual household water and energy expenditures are typically a small fraction of annual income [19], [29], [32]. Though in the general case the difference between conditional and unconditional elasticities under IBPs cannot be signed, what we observe may be typical in the context of water demand. 


\section{REFERENCES}

[1] Organization for Economic Cooperation and Development, Household water pricing in OECD countries, OECD, Paris (1999).

[2] Raftelis Environmental Consulting Group, Inc., "Raftelis Environmental Consulting Group 1998 Water and Wastewater Rate Survey," Raftelis Environmental Consulting, Charlotte, NC (1999).

[3] K. D. Frederick and G. E. Schwarz, Socioeconomic impacts of climate variability and change on U.S. water resources, RFF Discussion Paper 00-21, Resources for the Future, Washington, DC (2000).

[4] W. M. Hanemann, Prices and rate structures, in "Urban Water Demand Management and Planning” (D. Baumann, J. Boland and W. Hanemann, Eds.), McGraw-Hill, New York (1997). [5] C. Timmins, Demand-side technology standards under inefficient pricing regimes: Are they effective water conservation tools in the long run?, Environ. Res. Econom. 26, 107-124 (2003). [6] J. E. T. Moncur and R. L. Pollock, Scarcity rents for water: A valuation and pricing model, Land Econom. 64, 62-72 (1988).

[7] D. C. Hall, Public choice and water rate design, in "The Political Economy of Water Pricing Implementation" (A. Dinar, Ed.), Oxford, New York (2000).

[8] M. Espey, J. Espey and W. D. Shaw (1997), Price elasticity of residential demand for water: A meta-analysis, Water Resources Res. 33, 1369-1374 (1997).

[9] J. M. Dalhuisen, R. J. G. M. Florax, H. L. F. de Groot and P. Nijkamp, Price and income elasticities of residential water demand: A meta-analysis, Land Econom. 79, 292-308 (2003). 
[10] R. Moffitt, The econometrics of kinked budget constraints, J. Econom. Perspect. 4, 119-139 (1990).

[11] R. Moffitt, The econometrics of piecewise-linear budget constraints: A survey and exposition of the maximum likelihood method, J. Bus. Econom. Statist. 4, 317-328 (1986).

[12] G. Burtless and J. A. Hausman, The effect of taxation on labor supply: Evaluating the Gary income maintenance experiment, J. Pol. Econom. 86, 1101-1130 (1978).

[13] J. A. Hausman, Taxes and labor supply, in "The Handbook of Public Economics" (A. Auerbach and M. Feldstein, Eds.), North-Holland, Amsterdam (1985).

[14] J. A. Hewitt, Watering households: The two-error discrete-continuous choice model of residential water demand, Ph.D. Dissertation, University of California, Berkeley, CA (1993). [15] J. A. Hewitt and W. M. Hanemann, A discrete/continuous choice approach to residential water demand under block rate pricing, Land Econom. 71, 173-192 (1995).

[16] E. M. Pint, Household responses to increased water rates during the California drought, Land Econom. 75, 246-266 (1999).

[17] C. W. Howe and F. P. Lineweaver, The impact of price on residential water demand and its relation to system demand and price structure, Water Resources Res. 3, 13-32 (1967).

[18] L. E. Danielson, An analysis of residential demand for water using micro time-series data, Water Resources Res. 22, 763-767 (1979).

[19] S. C. Deller, D. L. Chicoine and G. Ramamurthy, Instrumental variables approach to rural water service demand, South. Econom. J. 53, 333-346 (1986).

[20] M. L. Nieswiadomy and S. L. Cobb, Impact of pricing structure selectivity on urban water demand, Contemp. Policy Issues 11, 101-113 (1993). 
[21] S. Gaudin, Effect of price information on residential water demand, Appl. Econom. 38, 383-393 (2006).

[22] J. B. Liebman and R. J. Zeckhauser, Schmeduling, Working Paper, Kennedy School of Government, Harvard University (2004).

[23] W. M. Hanemann, Discrete/continuous models of consumer demand, Econometrica 52, 541-561 (1984).

[24] P. Rietveld, J. Rouwendal and B. Zwart, Equity and efficiency in block rate pricing: Estimating water demand in Indonesia, Tinbergen Institute Discussion Paper No. 97-072/3, Tinbergen Institute, Amsterdam (1997).

[25] R. E. Hall, Wages, income and hours of work in the U.S. labor force, in "Income Maintenance and Labor Supply” (G. Cain and H. Watts, Eds.), Rand McNally, Chicago (1973). [26] J. A. Nordin, J. A., A proposed modification of Taylor's demand analysis: Comment, Bell J. Econom. 7, 719-21 (1976).

[27] L. D. Taylor, The demand for electricity: A survey, Bell J. Econom. 6, 74-110 (1975).

[28] R. Billings and D. E. Agthe, Price elasticities for water: A case of increasing block rates, Land Econom. 56, 73-84 (1980).

[29] J. A. Hausman, M. Kinnucan and D. McFadden, A two-level electricity demand model: Evaluation of the Connecticut time-of-day pricing test, J. Econom. 10, 263-289 (1979).

[30] D. E. Agthe, R. Billings, J. L. Dobra and K. Raffiee, A simultaneous equation demand model for block rates, Water Resources Res. 22, 1-4 (1986).

[31] M. L. Nieswiadomy and D. J. Molina, Urban water demand estimates under increasing block rates, Growth and Change 19, 1-12 (1988). 
[32] M. L. Nieswiadomy and D. J. Molina, Comparing residential water demand estimates under decreasing and increasing block rates using household data, Land Econom. 65, 280-289 (1989). [33] S. M. Olmstead, Reduced-form vs. structural models of water demand, J. Bus. Econ. Statist., forthcoming (2007).

[34] P. W. Mayer, W. B. DeOreo, E. M. Opitz, J. C. Kiefer, W. Y. Davis, B. Dziegielewski and J. O. Nelson, "Residential End Uses of Water,"American Water Works Association Research Foundation, Denver (1988).

[35] E. T. Mansur and S. M. Olmstead, The value of scarce water: Measuring the inefficiency of municipal regulations, Working Paper (2006).

[36] J. A. Hausman, Labor supply, in "How Taxes Affect Economic Behavior" (H. Aaron and J. Pechman, Eds.), Brookings Institution, Washington, DC (1981). 
Table 1. Descriptive Statistics

\begin{tabular}{|c|c|c|c|c|c|c|}
\hline Variable & Description & Units & Mean & $\begin{array}{l}\text { Std. } \\
\text { Dev. }\end{array}$ & Min. & Max. \\
\hline $\mathrm{w}$ & Daily household water demand & $\mathrm{kgal} /$ day & 0.40 & 0.58 & 0.00 & 9.78 \\
\hline $\mathrm{p}_{1}$ & Marginal price in block 1 & $\$ / \mathrm{kgal}$ & 1.45 & 0.54 & 0.50 & 3.70 \\
\hline $\mathrm{p}_{2}$ & Marginal price in block 2 & $\$ / \mathrm{kgal}$ & 1.84 & 0.40 & 0.84 & 4.06 \\
\hline $\mathrm{p}_{3}$ & Marginal price in block 3 & $\$ / \mathrm{kgal}$ & 2.43 & 0.87 & 0.93 & 4.96 \\
\hline $\mathrm{p}_{4}$ & Marginal price in block 4 & $\$ / \mathrm{kgal}$ & 3.28 & 1.30 & 0.99 & 5.98 \\
\hline income & Gross annual household income & $\$ 000 / \mathrm{yr}$ & 69.81 & 67.67 & 5.00 & 388.64 \\
\hline $\mathrm{w}_{1}$ & Water quantity at kink 1 & $\mathrm{kgal} /$ day & 0.21 & 0.08 & 0.06 & 0.37 \\
\hline $\mathrm{w}_{2}$ & Water quantity at kink 2 & $\mathrm{kgal} /$ day & 0.36 & 0.09 & 0.30 & 0.50 \\
\hline $\mathrm{w}_{3}$ & Water quantity at kink 3 & $\mathrm{kgal} /$ day & 1.82 & 0.80 & 0.75 & 2.49 \\
\hline blockp & Price structure: 1 if IBP; 0 if UP & $0 / 1$ & 0.61 & 0.49 & 0 & 1 \\
\hline seas & Season: 1 if irrigation season; 0 if not & $0 / 1$ & 0.51 & 0.50 & 0 & 1 \\
\hline weath & Evapotranspiration less effective rainfall & $\mathrm{mm}$ & 5.06 & 8.42 & -46.15 & 19.37 \\
\hline $\operatorname{maxt}$ & Maximum daily temperature & ${ }^{\circ} \mathrm{C}$ & 24.12 & 8.78 & 0 & 42.78 \\
\hline famsz & Number of residents in household & number & 2.79 & 1.34 & 1 & 9 \\
\hline bthrm & Number of bathrooms in household & number & 2.58 & 1.30 & 1 & 7 \\
\hline sqft & Approximate area of home & $000 \mathrm{ft}^{2}$ & 2.02 & 0.82 & 0.40 & 4.37 \\
\hline lotsz & Approximate area of lot & $000 \mathrm{ft}^{2}$ & 10.87 & 9.22 & 1.00 & 45.77 \\
\hline age & Approximate age of home & $\mathrm{yrs} / 10$ & 2.88 & 1.62 & 0.07 & 5 \\
\hline evap & Evaporative cooling: 1 if yes; 0 if no & $0 / 1$ & 0.09 & 0.28 & 0 & 1 \\
\hline
\end{tabular}

Notes: City fixed effects not summarized here. Approximately 10 percent of observations drawn from each city (Las Virgenes Municipal Water District, Seattle, San Diego, Tampa, Phoenix, Tempe/Scottsdale, Waterloo/Cambridge, Walnut Valley Water District, Lompoc). 
Table 2. Water Demand Model Estimates

\begin{tabular}{|c|c|c|c|c|}
\hline & \multirow{2}{*}{$\begin{array}{c}\text { DCC } \\
\text { Full Sample }\end{array}$} & \multicolumn{2}{|c|}{ Split Sample Models } & \multirow{2}{*}{$\begin{array}{c}\text { DCC } \\
\text { Full Sample } \\
\text { Block Pricing Test }\end{array}$} \\
\hline & & $\begin{array}{c}\text { DCC } \\
\text { IBP Households Only }\end{array}$ & $\begin{array}{l}\text { Random Effects } \\
\text { UP Households Only }\end{array}$ & \\
\hline Variable & (1) & (2) & (3) & (4) \\
\hline \multirow[t]{2}{*}{ lnprice } & $-0.3407^{*}$ & $-0.6411 *$ & -0.3258 & $-0.2330 *$ \\
\hline & $(0.0298)$ & $(0.0424)$ & $(0.5644)$ & $(0.0677)$ \\
\hline \multirow[t]{2}{*}{ blockp*Inprice } & & & & $-0.1106^{\#}$ \\
\hline & & & & $(0.0626)$ \\
\hline \multirow[t]{2}{*}{ Inincome } & $0.1306^{*}$ & $0.1959 *$ & 0.0432 & $0.1308^{*}$ \\
\hline & $(0.0118)$ & $(0.0163)$ & $(0.0499)$ & $(0.0118)$ \\
\hline \multirow[t]{2}{*}{ seas } & $0.3072 *$ & $0.3370^{*}$ & $0.2656^{*}$ & $0.3075^{*}$ \\
\hline & $(0.0247)$ & $(0.0330)$ & $(0.0331)$ & $(0.0247)$ \\
\hline \multirow[t]{2}{*}{ weath } & $0.0079 *$ & $0.0094 *$ & $0.0054^{*}$ & $0.0076^{*}$ \\
\hline & $(0.0013)$ & $(0.0017)$ & $(0.0016)$ & $(0.0013)$ \\
\hline \multirow[t]{2}{*}{$\operatorname{maxt}$} & $0.0196^{*}$ & $0.0238^{*}$ & $0.0193^{*}$ & $0.0200^{*}$ \\
\hline & $(0.0018)$ & $(0.0024)$ & $(0.0025)$ & $(0.0018)$ \\
\hline \multirow[t]{2}{*}{ famsz } & $0.1960^{*}$ & $0.1959^{*}$ & $0.2095^{*}$ & $0.1957^{*}$ \\
\hline & $(0.0056)$ & $(0.0080)$ & $(0.0225)$ & $(0.0056)$ \\
\hline \multirow[t]{2}{*}{ bthrm } & $0.0585^{*}$ & $0.0553 *$ & 0.0498 & $0.0590^{*}$ \\
\hline & $(0.0093)$ & $(0.0127)$ & $(0.0393)$ & $(0.0093)$ \\
\hline \multirow[t]{2}{*}{ sqft } & $0.1257 *$ & $0.2001 *$ & -0.0066 & $0.1253^{*}$ \\
\hline & $(0.0140)$ & $(0.0191)$ & $(0.0600)$ & $(0.0140)$ \\
\hline \multirow[t]{2}{*}{ lotsz } & $0.0065^{*}$ & $0.0097 *$ & -0.0010 & $0.0064^{*}$ \\
\hline & $(0.0009)$ & $(0.0011)$ & $(0.0046)$ & $(0.0009)$ \\
\hline \multirow[t]{2}{*}{ age } & $0.0869^{*}$ & $0.1814^{*}$ & -0.0870 & $0.0888^{*}$ \\
\hline & $(0.0219)$ & $(0.0304)$ & $(0.0940)$ & $(0.0219)$ \\
\hline \multirow[t]{2}{*}{ age2 } & $-0.0137 *$ & $-0.0252 *$ & 0.0109 & $-0.0141^{*}$ \\
\hline & $(0.0036)$ & $(0.0050)$ & $(0.0160)$ & $(0.0036)$ \\
\hline \multirow[t]{2}{*}{ evap } & $0.2278 *$ & $0.2416^{*}$ & -0.8139 & $0.2281^{*}$ \\
\hline & $(0.0300)$ & $(0.0334)$ & $(0.6129)$ & $(0.0300)$ \\
\hline \multirow[t]{2}{*}{ lasv } & $0.2590 *$ & $0.3391 *$ & & $0.2570^{*}$ \\
\hline & $(0.0408)$ & $(0.0486)$ & & (0.0409) \\
\hline
\end{tabular}




\begin{tabular}{|c|c|c|c|c|}
\hline & \multirow{2}{*}{$\begin{array}{c}\text { DCC } \\
\text { Full Sample }\end{array}$} & \multicolumn{2}{|c|}{ Split Sample Models } & \multirow{2}{*}{$\begin{array}{c}\text { DCC } \\
\text { Full Sample } \\
\text { Block Pricing Test }\end{array}$} \\
\hline & & $\begin{array}{c}\text { DCC } \\
\text { IBP Households Only }\end{array}$ & $\begin{array}{l}\text { Random Effects } \\
\text { UP Households Only }\end{array}$ & \\
\hline Variable & (1) & (2) & (3) & (4) \\
\hline \multirow[t]{2}{*}{ seat } & $-0.1232^{*}$ & -0.0482 & & $-0.1566^{*}$ \\
\hline & $(0.0379)$ & $(0.0491)$ & & $(0.0424)$ \\
\hline \multirow[t]{2}{*}{ sandg } & 0.0129 & $0.1361^{*}$ & & 0.0114 \\
\hline & $(0.0365)$ & $(0.0416)$ & & $(0.0366)$ \\
\hline \multirow[t]{2}{*}{ tampa } & $-0.3879^{*}$ & $-0.3225^{*}$ & & $-0.3919^{*}$ \\
\hline & $(0.0373)$ & $(0.0427)$ & & $(0.0374)$ \\
\hline \multirow[t]{2}{*}{ phx } & -0.0044 & -0.0271 & & -0.0086 \\
\hline & $(0.0385)$ & $(0.0444)$ & & $(0.0387)$ \\
\hline \multirow[t]{2}{*}{ tscot } & $-0.1033^{*}$ & $-0.1436^{*}$ & & $-0.1064 *$ \\
\hline & $(0.0359)$ & $(0.0406)$ & -0.0018 & $(0.0360)$ \\
\hline \multirow[t]{2}{*}{ eug } & 0.0050 & & $(0.5846)$ & 0.0340 \\
\hline & $(0.0387)$ & & -0.1646 & $(0.0420)$ \\
\hline \multirow[t]{2}{*}{ wcamb } & $-0.1939^{*}$ & & $(0.1568)$ & $-0.2545^{*}$ \\
\hline & $(0.0362)$ & & $0.3272 *$ & $(0.0499)$ \\
\hline \multirow[t]{2}{*}{ wvall } & $0.1784^{*}$ & & $(0.1320)$ & $0.1021^{\#}$ \\
\hline & $(0.0387)$ & & -0.0440 & $(0.0580)$ \\
\hline \multirow[t]{2}{*}{ lomp } & -0.0647 & & $(0.1132)$ & $-0.1512^{*}$ \\
\hline & $(0.0373)$ & & $-3.1353^{*}$ & $(0.0615)$ \\
\hline \multirow[t]{2}{*}{ constant } & $-3.6994 *$ & $-4.3288^{*}$ & $(0.6854)$ & $-3.7068^{*}$ \\
\hline & $(0.0652)$ & $(0.0888)$ & & $(0.0654)$ \\
\hline \multirow[t]{2}{*}{$\sigma_{\eta}$} & $1.0769 *$ & $1.1493^{*}$ & & $1.0767 *$ \\
\hline & $(0.0103)$ & $(0.0115)$ & & $(0.0103)$ \\
\hline \multirow[t]{2}{*}{$\sigma_{\varepsilon}$} & $0.3552 *$ & $0.4220^{*}$ & & $0.3562 *$ \\
\hline & $(0.0277)$ & $(0.0227)$ & & $(0.0277)$ \\
\hline
\end{tabular}

Notes: *Significant at $\alpha=.05$. "Significant at $\alpha=.10$. Standard errors in parentheses below estimates. Dependent variable is natural log of daily water demand. Models in columns 1,2 and 4 are discrete/continuous choice (DCC), estimated by maximum likelihood. Model in column 3 is random effects GLS regression. City fixed effects are relative to Denver, CO, except in column 3, where they are relative to Seattle, WA. For full-sample models (columns 1 and 4), $\mathrm{N}=25,666$. For IBP split-sample model (column 2), $\mathrm{N}=15,621$; and for UP split-sample model (column 3), $\mathrm{N}=10,045$. 
Table 3. Simulated Price and Income Elasticities of Demand

\begin{tabular}{|c|c|c|c|c|}
\hline \multirow[b]{3}{*}{ Discrete Continuous Choice Model } & \multicolumn{4}{|c|}{ Elasticity Estimates } \\
\hline & \multicolumn{2}{|c|}{ Parametric } & \multicolumn{2}{|c|}{ Nonparametric } \\
\hline & Price & Income & Price & Income \\
\hline Full sample & $\begin{array}{l}-0.3309 * \\
(0.0062)\end{array}$ & $\begin{array}{c}0.1261 * \\
(0.0031)\end{array}$ & $\begin{array}{l}-0.3319 * \\
(0.0366)\end{array}$ & $\begin{array}{c}0.1273 * \\
(0.0133)\end{array}$ \\
\hline Increasing-block households only & $\begin{array}{l}-0.5893 * \\
(0.0437)\end{array}$ & $\begin{array}{c}0.1786^{*} \\
(0.0138)\end{array}$ & $\begin{array}{l}-0.6090 * \\
(0.0568)\end{array}$ & $\begin{array}{c}0.1865^{*} \\
(0.0159)\end{array}$ \\
\hline Random Effects Model & \multicolumn{2}{|c|}{ Price } & \multicolumn{2}{|c|}{ Income } \\
\hline Uniform price households only & \multicolumn{2}{|c|}{$\begin{array}{l}-0.3258 \\
(0.5644)\end{array}$} & \multicolumn{2}{|c|}{$\begin{array}{c}0.0432 \\
(0.0499)\end{array}$} \\
\hline
\end{tabular}

Notes: *Significant at $\alpha=.05$. Reported estimates are the means of bootstrapped elasticities, and reported standard errors (in parentheses) are the standard deviations of bootstrapped elasticities. Simulated DCC elasticity estimates for variables other than price and income do not vary appreciably from coefficient estimates reported in Table 2. Elasticity estimates for random effects model are repeated from Table 2, for comparison purposes (no simulations necessary for this model.) 


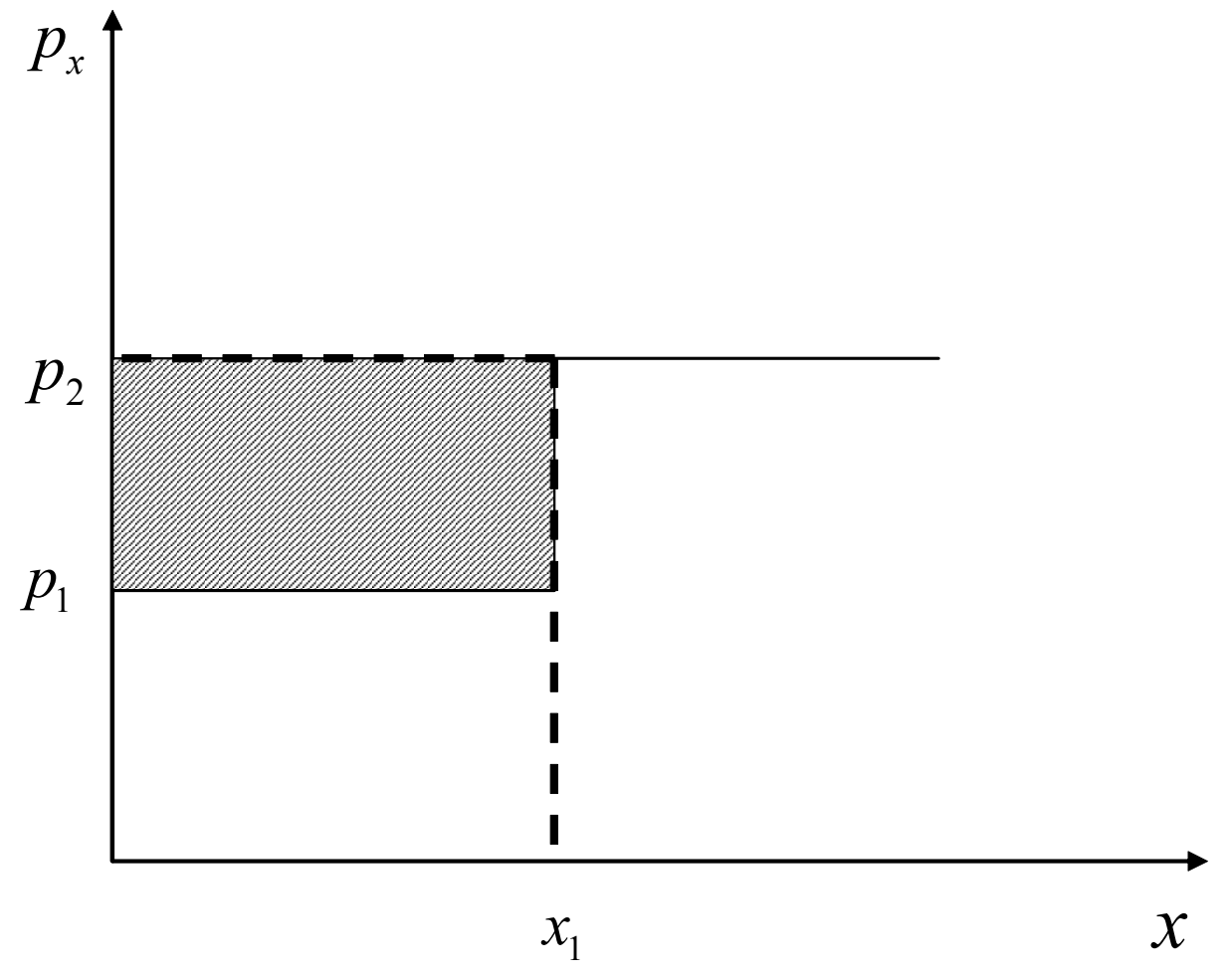

Figure 1. Two-tier increasing block price structure, in which $w$ is water (units); $p_{1}$ the marginal price of water in block $1 ; p_{2}$ the marginal price of water in block 2 ; and $w_{1}$ the boundary quantity between blocks. 


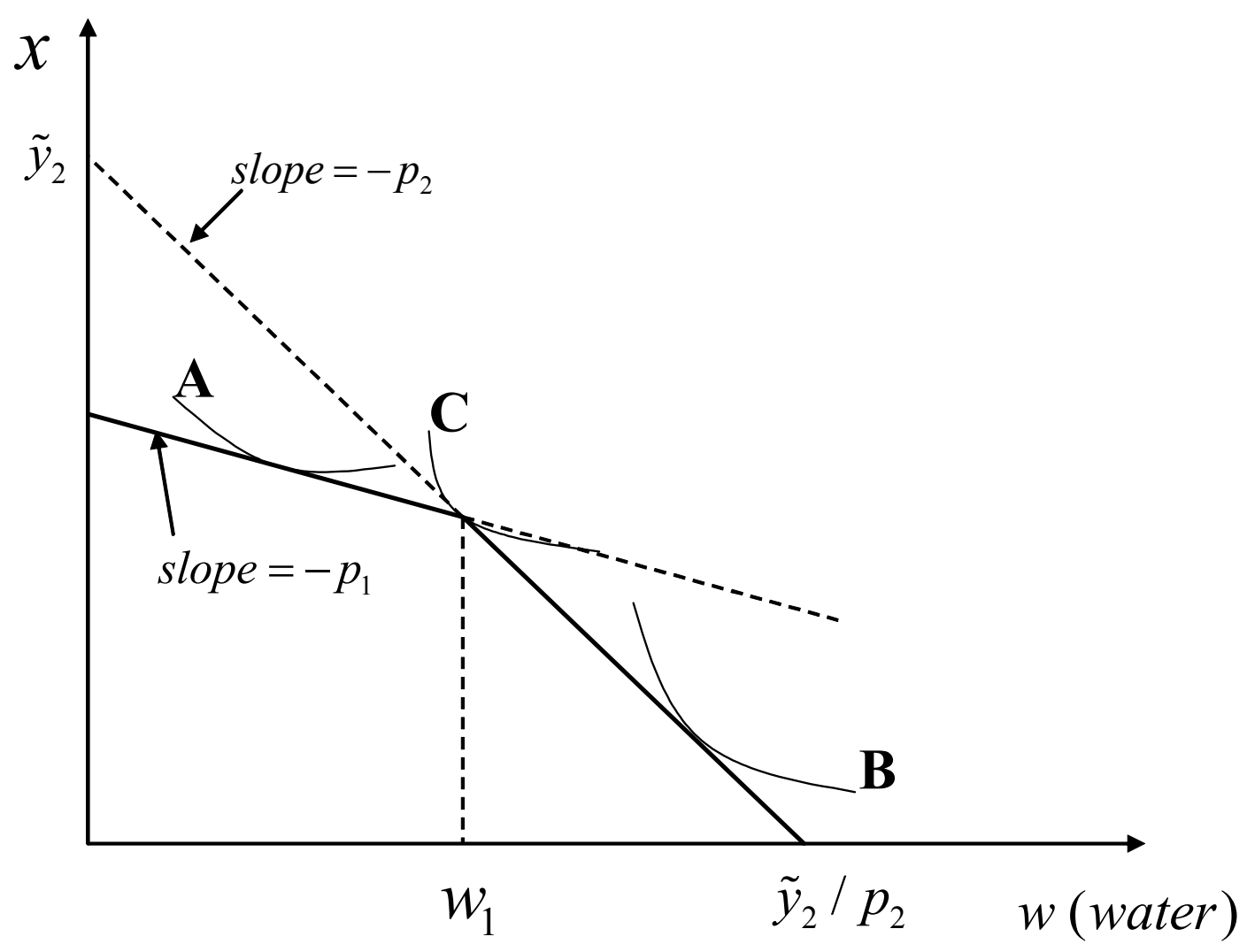

Figure 2. Utility maximization under a two-tier increasing block price structure, where $\mathrm{x}$ is all goods other than water, and $y$ is income. 